\title{
Electrical Property Improvement of Copper Filler Conductive Adhesive with Low- Melting Point Metal Bridge
}

\author{
Michiya Matsushima*, Yusuke Takechi, Shogo Minami, Shinji Fukumoto and Kozo Fujimoto \\ Graduate School of Engineering, Osaka University, Suita 565-0871, Japan
}

Conductive adhesives are expected to be the solder alternative bonding materials in low temperature joining. However, the thermal resistivity and electrical resistivity are higher than those of solders. The contact resistances between the metal fillers and resin intrusion are considered to cause the high resistivity. To solve these problems, metallic cross-links are generated between the copper fillers in the conductive adhesives. Low melting point metal (SnBi) fillers which would be molten under curing temperature of the resin are mixed with copper fillers in the resin. In the curing process, the molten $\mathrm{SnBi}$ form the metallic bond cross-link between them. In this paper, the electrical resistivity as well as the thermal resistivity depending on the mixture ratio, size of fillers and the SnBi cross-link are investigated through the experiments. [doi:10.2320/matertrans.MH201810]

(Received December 28, 2018; Accepted June 3, 2019; Published July 12, 2019)

Keywords: low temperature joining, conductive adhesive, low melting point metal, thermal conductivity, electrical resistivity

\section{Introduction}

The melting point of $\mathrm{Sn}-3.0 \mathrm{Ag}-0.5 \mathrm{Cu}$ which is a lead free solder standardized in Japan is $219^{\circ} \mathrm{C}$. It is higher than the one of tin-lead eutectic solder $\left(183^{\circ} \mathrm{C}\right)$ which was used before enforcement of RoHS (restriction of the use of certain hazardous substances in electrical and electronic equipment) directive. Increase of heating in assembly process causes the problems such as the damages of electronics devices or residual stress due to the linear expansion coefficient difference. Therefore, alternative assembly materials which enable to assemble at the same or lower temperature than tin-lead eutectic solder is required. ${ }^{1,2)}$ One of the candidates is conductive adhesive. Conductive adhesive is composite material of organic binder and conductive metal fillers. The conductivity is achieved by metal fillers and the structure strength depends on the organic binder such as epoxy resin. The joint is durable to high temperature with low temperature bonding process because the epoxy resin is a thermosetting material. ${ }^{3-6)}$ However, the conventional conductive adhesives are inferior to the solder in thermal and electrical conductivity. ${ }^{7,8)}$ Table 1 represents the properties of typical conductive adhesive of epoxy resin with silver fillers. ${ }^{9}{ }^{9}$

The purpose of this study is to improve the conductivity of conductive adhesives as an alternative material of solder.

The conductive mechanism in conductive adhesives are considered that the contacts of each filler is prompted by resin shrinkage. ${ }^{10)}$ The presence of contact resistance and the resistance due to the resin layer between fillers cause the poor electrical and thermal conductivity as compared with solder. Therefore, we proposed the bridge structure with low melting point metal in order to increase the contact area and reduction of contact resistance. The bridges between metal fillers are formed by thermosetting the epoxy resin at higher temperature than the melting point of low melting point metal particles contained in the conductive adhesive with nonmolten filler. $\mathrm{SnBi}$ eutectic particles having a melting point of $139^{\circ} \mathrm{C}$ and $\mathrm{Cu}$ particles are used as low melting point metal filler and non-molten filler respectively. Several previous

*Corresponding author, E-mail: matsushima@mapse.eng.osaka-u.ac.jp studies have reported about electrical characteristic, adhesive strength and reliability of conductive adhesives with similar composites. ${ }^{11-13)}$ In this paper, the effect of bridging low melting point metal and the filler size in the conductive adhesive on the thermal and electrical conductivity is investigated.

\section{Specimens and Experimental Method}

\subsection{Measurement of thermal conductivity}

The conductive adhesive used in this experiments consist of epoxy resin as binder, $\phi 100 \mu \mathrm{m}$ copper spherical particle as non-molten filler, and $\phi 73 \mu \mathrm{m}$ and $\phi 20 \mu \mathrm{m}$ tin-bismuth eutectic particle as low melting point metal.

The bis-phenol F-type alicyclic epoxy resin contains acid anhydride curing agent with a reduction action simultaneously in curing (Fujikura Kasei Co., Ltd.). This resin and $\phi 100 \mu \mathrm{m} 99.9+\%$ copper fillers were compounded to fabricate the thermal resistance specimens. Two $99.96 \%$ copper disks with dimensions of $\phi 10 \mathrm{~mm} \times 3 \mathrm{~mm}$ were used for the bonded materials. A $\phi 1 \mathrm{~mm} \times 5 \mathrm{~mm}$ hole for measuring with thermo-coupling on the side of the copper disk. As a pre-processing step for the metal surface process, the metals were polished using \#120 to \#4000 emery paper. The samples were pickled with $5 \%$ hydrochloric acid and wash with ethanol for $180 \mathrm{~s}$.

The epoxy resin and metal fillers are kneaded in vacuum mixer under condition of $2000 \mathrm{rpm}$ and $0.6 \mathrm{kPa}$ for $300 \mathrm{~s}$. Figure 1 shows the specimen for thermal conductivity measurement. Ni wires of $\phi 300 \mu \mathrm{m}$ are inserted as spacer to keep constant bonding layer thickness. The specimens are heated in infrared heating oven by the temperature profile shown in Fig. 2. The specimens are heated to $200^{\circ} \mathrm{C}$ by the increasing rate of $1{ }^{\circ} \mathrm{C} / \mathrm{s}$ and kept for $300 \mathrm{~s}$. The heating temperature of $120^{\circ} \mathrm{C}$ was also applied for confirming the effect of melting and bridging low melting point metal.

Thermal conductivity was measured with (Thermal Conductivity Measurement System. TCM1001: RHESCA CO., LTD) by steady state one-dimensional heat conduction method. ${ }^{14)}$ Figure 3 shows the equipment schematic view and example of measured temperature gradient. One side of the 
Table 1 Property of lead free solder and conductive adhesive.9)

\begin{tabular}{c|cc}
\hline & Sn-Ag-Cu & Ag-epoxy \\
\hline $\begin{array}{c}\text { Thermal conductivity } \\
{[\mathrm{W} / \mathrm{mK}]}\end{array}$ & 55 & 2.0 \\
$\begin{array}{c}\text { Electrical resistivity } \\
{[\Omega \mathrm{m}]}\end{array}$ & $1.1 \times 10^{-7}$ & $3.5 \times 10^{-6}$ \\
\hline
\end{tabular}

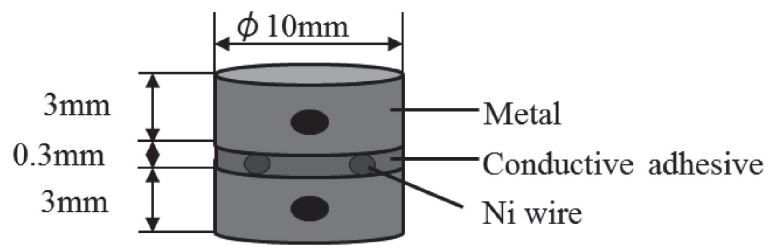

Fig. 1 Schematic illustration of heat conductivity measurement specimen.

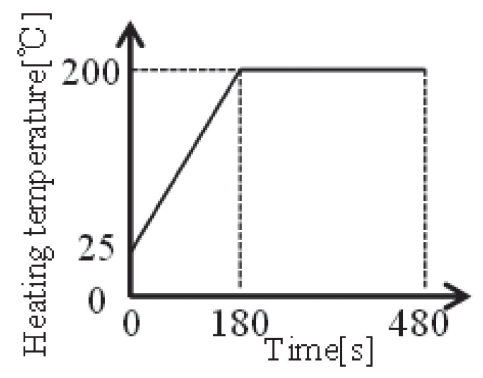

Fig. 2 Cure condition of conductive adhesive.

specimen was heated and the other side was cooled to generate a steady-state temperature gradient. The thermal resistance was calculated from the heat flux. The origin of the axis was set at the top of the rod, and assuming linear steady-state heat conduction, the temperature at each position was determined using eq. (1).

$$
T_{A}(x)=\left(\frac{d T}{d x}\right)_{A} x+T_{A}(0)
$$

The temperature at the rod edge $T_{A}(0)$ and the temperature gradient $\left(\frac{d T}{d x}\right)_{A}$ were approximated using the least squares method based on the temperatures $T_{A 0}, T_{A 1}, T_{A 2}$, and $T_{A 3}$ at the positions $x_{A 0}, x_{A 1}, x_{A 2}$, and $x_{A 3}$, respectively.

$$
\begin{gathered}
T_{A}(0)=\frac{\sum_{0}^{3} x_{A i}{ }^{2} \sum_{0}^{3} T_{A i}-\sum_{0}^{3} x_{A i} \sum_{0}^{3} x_{A i} T_{A i}}{4 \sum_{0}^{3} x_{A i}{ }^{2}-\left(\sum_{0}^{3} x_{A i}\right)^{2}} \\
\left(\frac{d T}{d x}\right)_{A}=\frac{4 \sum_{0}^{3} x_{A i} T_{A i}-\sum_{0}^{3} x_{A i} \sum_{0}^{3} T_{A i}}{4 \sum_{0}^{3} x_{A i}{ }^{2}-\left(\sum_{0}^{3} x_{A i}\right)^{2}}
\end{gathered}
$$

Based on eq. (1), the estimated temperature at the sample side edge of the upper rod $T_{A}\left(x_{A s}\right)$ was calculated using eq. (4):

$$
T_{A}\left(x_{A s}\right)=\frac{4 \sum_{0}^{3} x_{A i} T_{A i}-\sum_{0}^{3} x_{A i} \sum_{0}^{3} T_{A i}}{4 \sum_{0}^{3} x_{A i}{ }^{2}-\left(\sum_{0}^{3} x_{A i}\right)^{2}}
$$

(a)

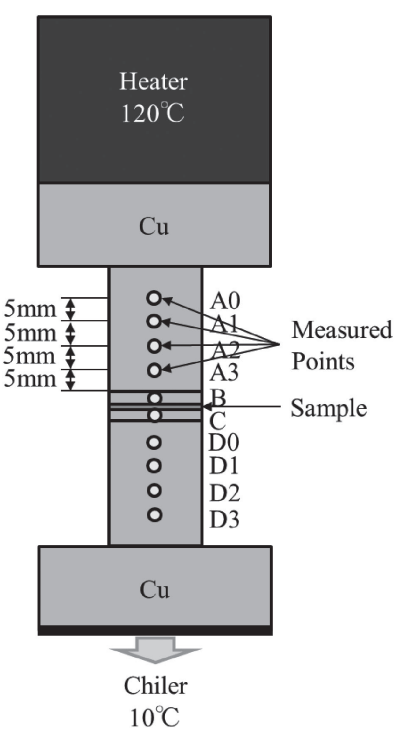

(b)

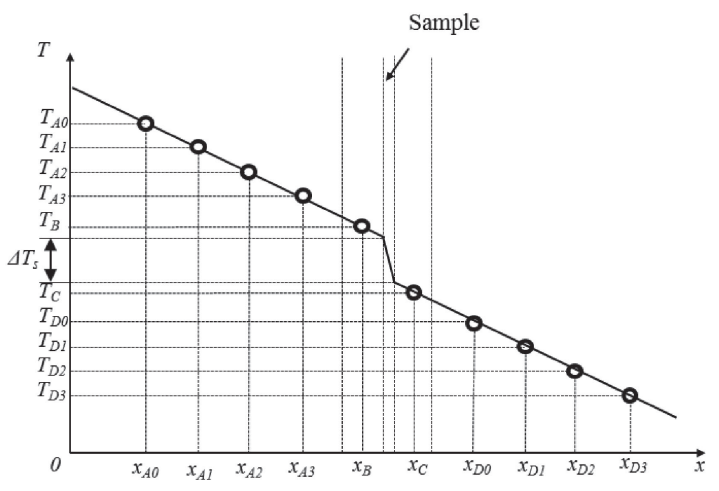

Fig. 3 Thermal conductivity measurement equipment. (a) Equipment with cylindrical rods and a sample. (b) Measurement points and the temperatures.

$$
+\frac{\sum_{0}^{3} x_{A i}{ }^{2} \sum_{0}^{3} T_{A i}-\sum_{0}^{3} x_{A i} \sum_{0}^{3} x_{A i} T_{A i}}{4 \sum_{0}^{3} x_{A i}{ }^{2}-\left(\sum_{0}^{3} x_{A i}\right)^{2}} .
$$

If $k_{A}$ is inserted as the thermal conductivity of the upper rod, the heat flux in the upper $\operatorname{rod} q_{A}$ is

$$
q_{A}=-k_{A}\left(\frac{d T}{d x}\right)_{A} .
$$

The temperature of the edge of the lower $\operatorname{rod} T_{D}\left(x_{D s}\right)$ and heat flux $q_{D}$ were also calculated in the same manner. The thermal conductivity $k_{s}$ was determined using eqs. (1)-(5) and the sample thickness $d t_{s}$ : 


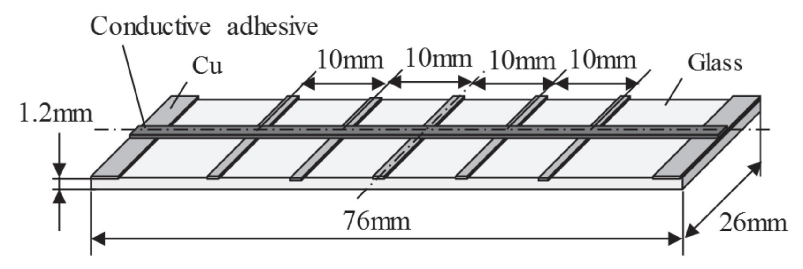

Fig. 4 Volume resistivity measurement specimen.

$$
k_{s}=\frac{\frac{1}{2}\left(q_{A}+q_{D}\right)}{T_{A}\left(x_{A s}\right)-T_{D}\left(x_{D s}\right)} d t_{s} .
$$

The thermal resistance $R s$ is the sample thickness multiplied by the reciprocal of the thermal conductivity.

In our experiment, the heater and chiller were set to $120^{\circ} \mathrm{C}$ and $10^{\circ} \mathrm{C}$, respectively. The thermal resistance value was calculated by averaging the measured values at 571 to $600 \mathrm{~s}$ from the start of heating.

\subsection{Measurement of electrical resistance}

Figure 4 shows the specimen image for measuring electrical resistance. The electrical resistances of the conductive adhesives are measured with four-terminal method. The conductive adhesives are cured on the glass substrate with dimension of $2.6 \times 7.6 \times \mathrm{t} 1.2 \mathrm{~mm}$ on which copper electrodes are placed. Two $4 \mathrm{~mm}$ width terminals on the both edges are for current and five $2 \mathrm{~mm}$ width terminals with $10 \mathrm{~mm}$ intervals are for measurement.

A volume resistivity measurement specimen was generated by mask-printing the prepared conductive adhesives with the width of $2 \mathrm{~mm}$ on the substrate.

The specimen is cured with the same temperature profile as in the case of making the specimen for the measurement of thermal conductivity shown in Fig. 2.

The electrical conductivity of the conductive adhesive was evaluated by calculating the volume resistivity from the resistance value of the measured with the 4-terminal method using a micro-ohm meter manufactured by Agilent. Current was applied from the electrode at the end of the test piece, and the resistance was measured at inter-electrode distance $\mathrm{g}=10,20,30$, and $40 \mathrm{~mm}$. From the relationship between the inter-electrode distance and the measured resistance value, the slope of the linearly approximated line is $\mathrm{R} / \mathrm{g}$, the thickness of the adhesive is $\mathrm{d}$, the width is $\mathrm{w}$, and the volume resistivity is obtained as follows.

$$
\rho=\frac{R d w}{g}
$$

\section{Effect of Filler Gaps on Thermal Conductivity}

The thermal conductivity of the conductive adhesive increases as the number of conduction paths in the adhesive increases. The route of the conduction path is mainly composed of contact portion between the metal fillers, and it is considered that the conduction path increases as the number of the filler contact increases, and the thermal conduction characteristics become better.
The conductivity becomes ideal when every filler makes contact with other fillers and make conductive path. However, it is considered that not all fillers are in contact with each other and resin layer is partially presence between the fillers in fact.

In the case where the average distance between all the fillers in the adhesive is defined as the inter-filler gap, the characteristics would be improved by bringing the inter-filler gap close to 0 . The gaps are decreased by increasing the volume fraction of the filler. Supposed

Assuming that the metal fillers are spherical shapes with the same particle diameters, patterns such as a simple cubic structure, a body-centered cubic structure, a face-centered cubic structure can be considered as an ideal filling state.

Figure 5 shows the relationship between the filler gap and volume fraction in each cubic structure. ${ }^{15)}$ The filler gap in Fig. 5 is represented by the filler gap ratio to the filler diameter $(\mathrm{t} / D)$. Thus, the volume content and the gap between fillers are dependent.

In order to investigate the actual dependence of the thermal conductivity and the gap between the fillers, samples were prepared in which the filler content was varied from 30 to $60 \mathrm{vol} \%$, and the thermal conductivity was measured. Figure 6 shows the measurement result. The thermal conductivity increases with the filler volume fraction increase and it was $8 \mathrm{~W} / \mathrm{mK}$ with $60 \mathrm{vol} \%$ filler content. It is necessary to increase the filler content to improve the thermal conductivity close to the thermal conductivity of solders.

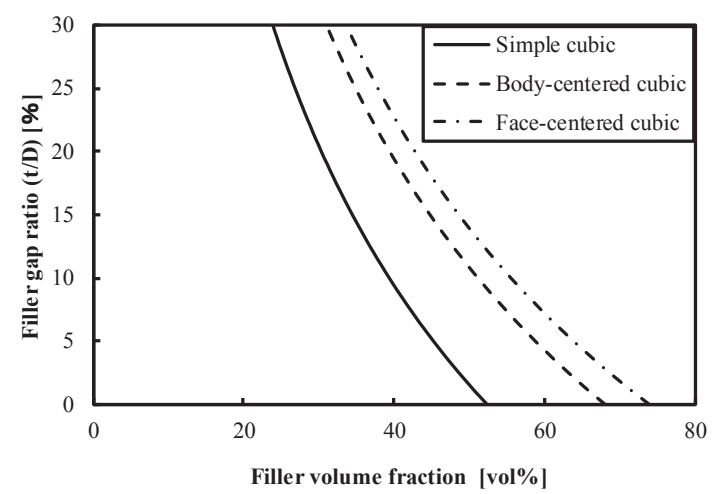

Fig. 5 Relationship between filler content ratio and filler gap in filling models.

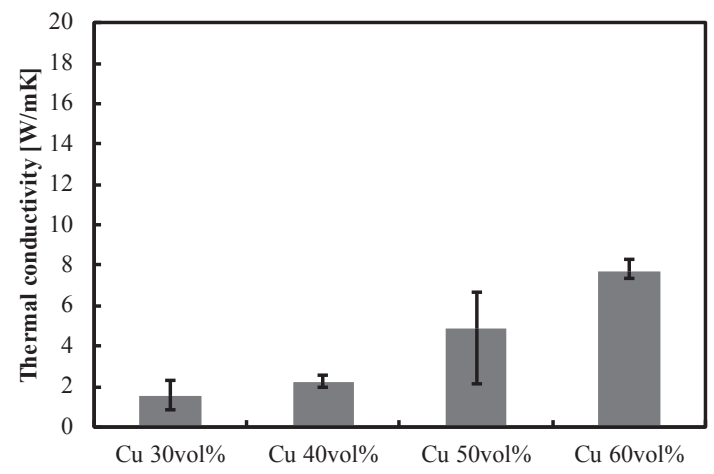

Fig. 6 Thermal conductivity with filler content ratio variation. 
(a)

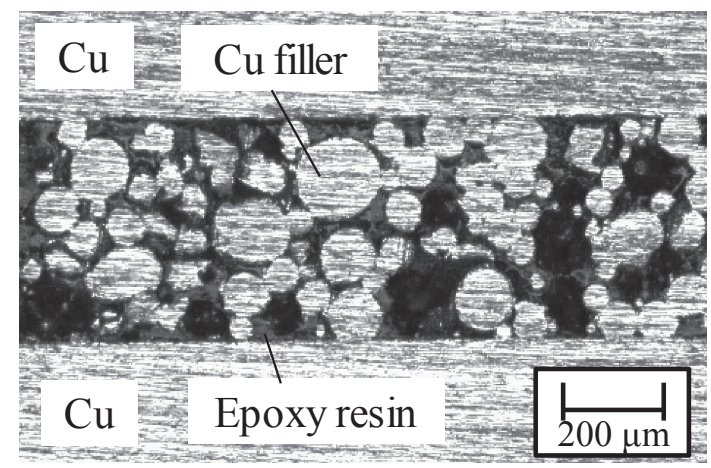

(b)

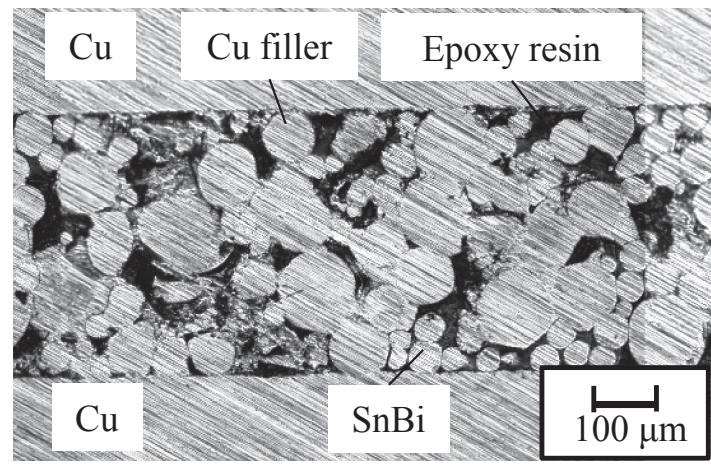

(c)

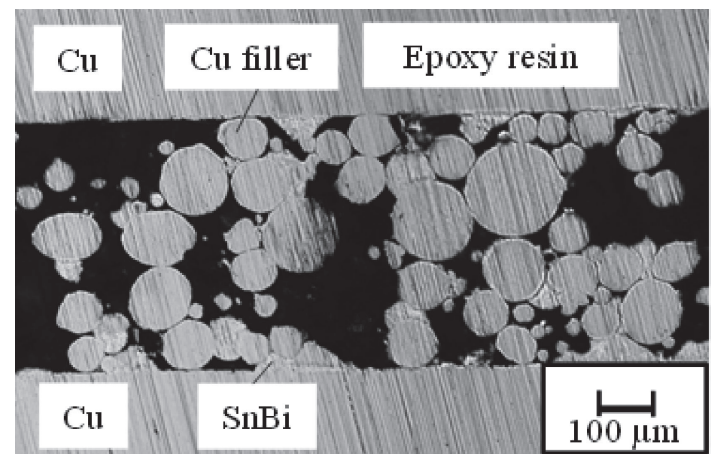

Fig. 7 Cross section of bonding layer depending on the curing temperature. (a) $\mathrm{Cu} 50$ vol\%. (b) $\mathrm{Cu} 50$ vol $\%$ and $\varphi 73 \mu \mathrm{m} \mathrm{SnBi} 10$ vol\% cured at $120^{\circ} \mathrm{C}$ (c) $\mathrm{Cu} 50 \mathrm{vol} \%$ and $\varphi 73 \mu \mathrm{m} \mathrm{SnBi} 10 \mathrm{vol} \%$ cured at $200^{\circ} \mathrm{C}$.

\section{Effect of Low Melting Point Metal Bridge on Thermal Conductivity}

Effect of $\mathrm{SnBi}$ bridging structure on the thermal conductivity characteristics was evaluated by measuring the thermal conductivity with or without $\mathrm{SnBi}$ bridging under the same $\mathrm{Cu} / \mathrm{SnBi}$ content. ${ }^{15)}$ Following two cases are compared: the case where bridge structures were formed by molten $\mathrm{SnBi}$ fillers and the case where the fillers remained as particles without melting. The contents of the conductive adhesives are $50 \mathrm{vol} \% \mathrm{Cu}$ fillers, $10 \mathrm{vol} \%$ of $\varphi 73 \mu \mathrm{m} \mathrm{SnBi}$ fillers. The cure temperatures are $200^{\circ} \mathrm{C}$ (over melting point) for $300 \mathrm{~s}$ and $120^{\circ} \mathrm{C}$ (under melting point) for $1800 \mathrm{~s}$. Figure 7 is the cross-section images of bonding layer of the specimens. SnBi fillers are remained without wetting on the $\mathrm{Cu}$ fillers in the specimen cured at $120^{\circ} \mathrm{C}$ (Fig. 7(a)) while the $\mathrm{SnBi}$ bridges are formed between the $\mathrm{Cu}$ fillers in the specimen cured at $200^{\circ} \mathrm{C}$ (Fig. 7(b)).

Figure 8 is the result of thermal conductivity measurement. The conductivity of the SnBi content samples increased $40 \%$

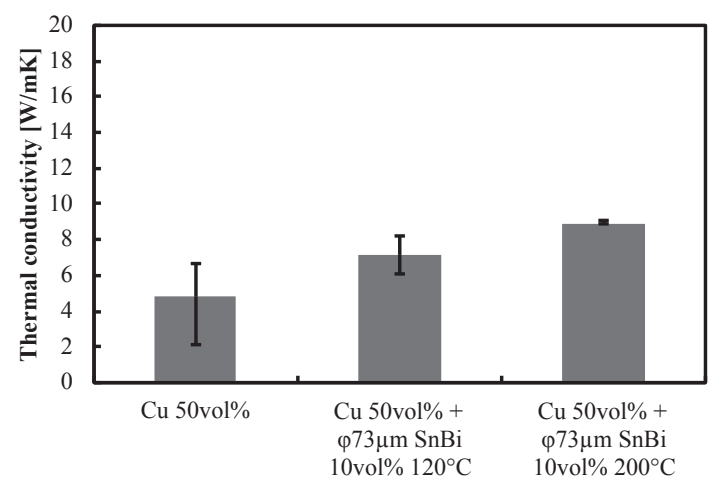

Fig. 8 Variation of thermal conductivity of $\mathrm{Cu} 50$ vol\% and SnBi 10 vol\% sample with curing temperature.

(a)

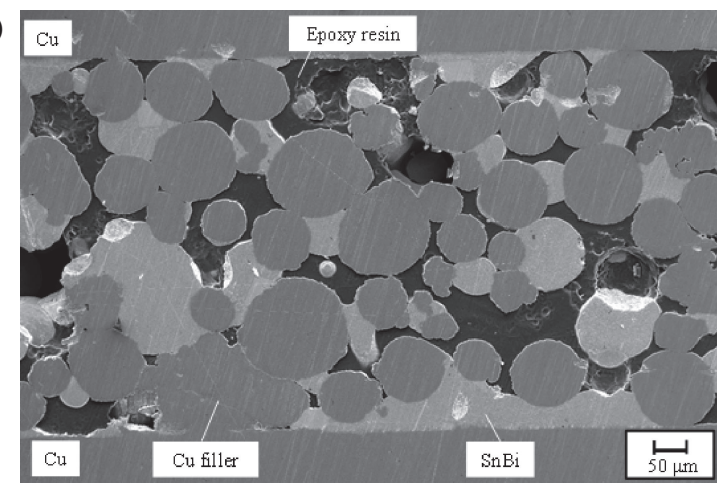

(b)

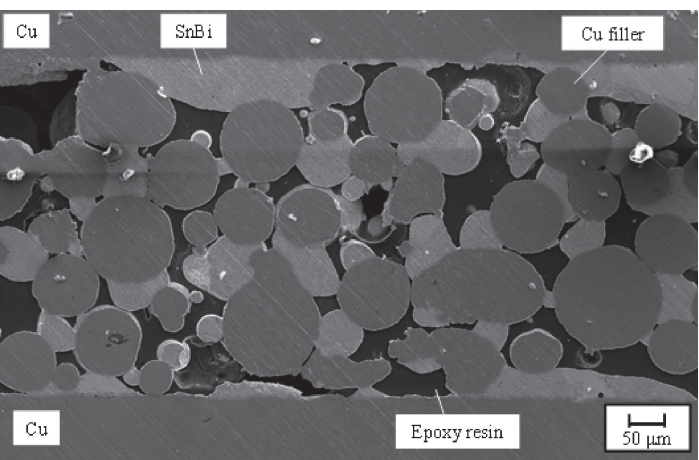

Fig. 9 SEM images of cross section of bonding layer.

with non-bridge sample and $80 \%$ with bridge sample compared to the $\mathrm{Cu} 50$ vol\% sample without $\mathrm{SnBi}$ fillers. Addition of $\mathrm{SnBi}$ fillers improved the thermal conductivity and the effect was more significant with curing at $200^{\circ} \mathrm{C}$. The improving effect of low melting point metal bridge was confirmed.

The effect of the size of low melting point metal filler added to the conductive adhesive was also investigated. The diameters of $73 \mu \mathrm{m}$ and $20 \mu \mathrm{m}$ SnBi fillers are added 20 vol\% to the adhesive with 50 vol\% $\mathrm{Cu}$ filler. The crosssection SEM images of those samples cured at $200^{\circ} \mathrm{C}$ are shown in Fig. 9(a) and (b) respectively. SnBi bridges between the $\mathrm{Cu}$ fillers or between $\mathrm{Cu}$ filler and $\mathrm{Cu}$ disk are observed and the conductive paths are formed in both samples. $\mathrm{Cu}-\mathrm{Sn}$ compound was observed at the interface between the $\mathrm{Cu}$ filler and $\mathrm{Sn}-\mathrm{Bi}$ bridge as mentioned in the previous research. ${ }^{13)}$ The measured thermal conductivities are shown in Fig. 10. The thermal conductivities of $\phi 73 \mu \mathrm{m}$ SnBi sample and 


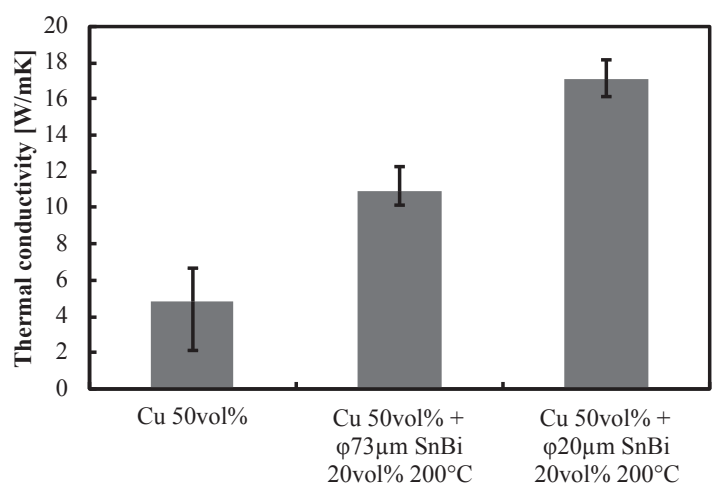

Fig. 10 Variation of thermal conductivity of $\mathrm{Cu} 50 \mathrm{vol} \%$ and $\mathrm{SnBi} 20 \mathrm{vol} \%$ sample with $\mathrm{SnBi}$ filler particle diameter.

$\phi 20 \mu \mathrm{m} \mathrm{SnBi}$ are $230 \%$ and $360 \%$ to the 50 vol\% $\mathrm{Cu}$ sample without $\mathrm{SnBi}$ filler respectively. It is considered that the $\phi 20 \mu \mathrm{m}$ SnBi sample showed more improvement than $\phi 73 \mu \mathrm{m}$ sample because the SnBi fillers are distributed uniformly and formed more conductive paths as shown in Fig. 9.

\section{Effect of Low Melting Point Metal Bridge on Electrical Conductivity}

Effect of filler content increase and the formation of low melting point metal bridges are experimentally evaluated. The volume resistivity of the bulk material of the conductive adhesive was measured by the method shown in Fig. 4. Samples in which the filler content was varied from 40 to 60 vol\% were prepared for evaluating the effect of $\mathrm{Cu}$ filler content. Samples of $\mathrm{Cu} 50 \mathrm{vol} \%+\varphi 73 \mu \mathrm{m}$ SnBi 10 vol\% are prepared for evaluating the effect of forming the $\mathrm{SnBi}$ bridges. And samples of $\mathrm{Cu} 50 \mathrm{vol} \%+\varphi 73 \mu \mathrm{m} \mathrm{SnBi}$ 20 vol\% and $\mathrm{Cu} 50 \mathrm{vol} \%+\varphi 20 \mu \mathrm{m}$ SnBi $20 \mathrm{vol} \%$ are prepared for evaluating the effect of $\mathrm{SnBi}$ particle diameter. The volume resistivities of these samples are measured. ${ }^{16)}$ The curing temperature profile is the same as the one for thermal conductivity specimen shown in Fig. 2. Figure 11 shows the relationship between volume resistivity and $\mathrm{Cu}$ filler content. The volume resistivity decrease as the $\mathrm{Cu}$ filler content increases and shows constant value over $50 \mathrm{vol} \%$. The typical Ag filler conductive adhesive has a volume resistivity about $3.5 \times 10^{-6} \Omega \mathrm{m}$. ${ }^{9}$ So the volume resistivities of these conductive adhesives are 2-3 digits higher than typical conductive adhesives. The reason of the high volume

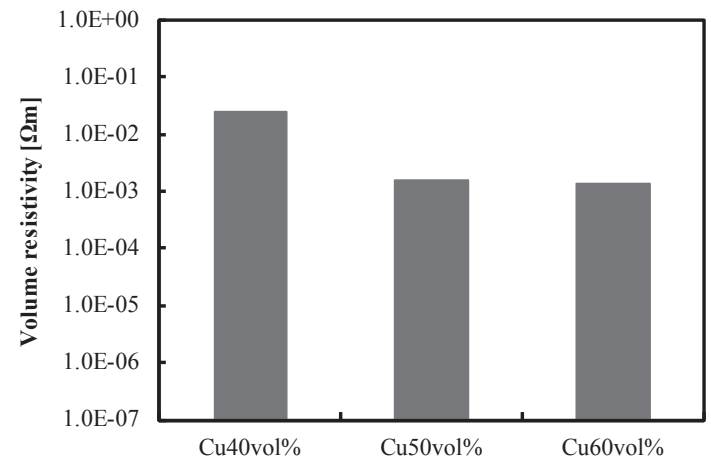

Fig. 11 Volume resistivity with filler volume fraction variation.

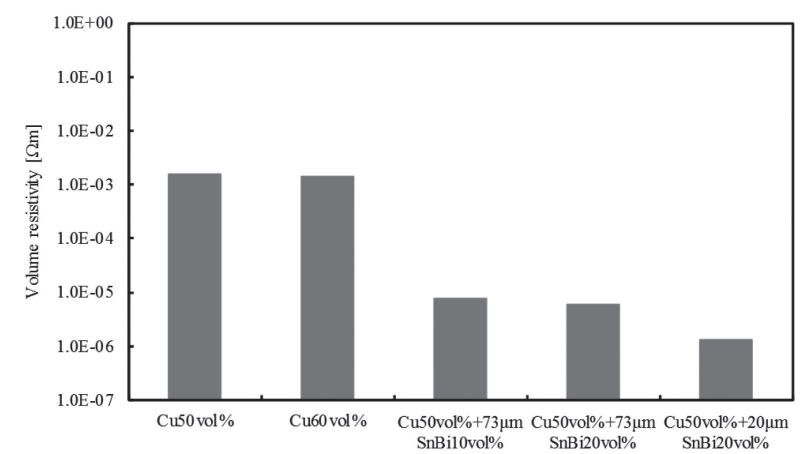

Fig. 12 Volume resistivity of $\mathrm{Cu} 50$ vol\%, $\mathrm{Cu} 60$ vol\% and $\mathrm{Cu} 50$ vol\% with $\mathrm{SnBi}$ sample with different $\mathrm{SnBi}$ filler particle diameter.

resistivity is presumed to be due to the oxidation of the $\mathrm{Cu}$ filler surface. The mechanism of electrical conductivity is mainly explained by percolation theory and is different from the mechanism of thermal conductivity. The electrical conductivity appears significantly at $50 \mathrm{vol} \%$ of $\mathrm{Cu}$ and saturated in Fig. 11.

Figure 12 shows the volume resistivity changes by adding $\mathrm{SnBi}$ fillers to $\mathrm{Cu} 50$ vol\% conductive adhesive. SnBi added samples shows lower resistivity by 2 digits than $\mathrm{Cu}$ filler samples. It is considered that this improvement was the effect of increased conductive paths by forming $\mathrm{SnBi}$ bridges between the $\mathrm{Cu}$ fillers. $\mathrm{Cu} 60$ vol\% sample and $\mathrm{Cu} 50$ vol\% with $\mathrm{SnBi} 10$ vol\% sample have the same metal contents. So the effect of the bridge formation was more significant than that of volume content increase. The volume resistivity of the $\phi 20 \mu \mathrm{m}$ SnBi sample showed more improvement than $\phi 73 \mu \mathrm{m}$ sample as well as the thermal conductivity. The significant decrease of volume resistivity is considered that the conductive paths increased between the $\mathrm{Cu}$ fillers by wetting of molten SnBi fillers broke the oxide layer of the $\mathrm{Cu}$ terminals and fillers. The low melting point metal bridges are effective to improve the electrical conductivity of $\mathrm{Cu}$ filler conductive adhesives.

\section{Conclusion}

The characteristics of the conductive adhesive containing the $\mathrm{SnBi}$ filler were evaluated and the results of examining the influence on the heat conductivity characteristics and electric resistivity due to formation of the metal filler bridge formation are shown below.

(1) As the result of measuring the thermal conductivity of the $\mathrm{SnBi}$ filler-added sample prepared at the curing temperature of $120^{\circ} \mathrm{C}$ and $200^{\circ} \mathrm{C}$, the thermal conductivity of the $120^{\circ} \mathrm{C}$ sample is about $40 \%$ and the $200^{\circ} \mathrm{C}$ sample is about $80 \%$ higher than the $\mathrm{Cu}$ 50 vol\% sample. It was shown that formation of bridge by molten $\mathrm{SnBi}$ improves thermal conductivity.

(2) As the result of measuring the thermal conductivity when changing the $\mathrm{SnBi}$ content to be added to the conductive adhesive, the thermal conductivity improved as the $\mathrm{SnBi}$ content increased and it was about twice as much as the $\mathrm{Cu} 50$ vol\% sample.

(3) As the result of measuring the thermal conductivity when the size of $\mathrm{SnBi}$ filler particle added to the 
conductive adhesive was changed, the thermal conductivity became higher as the $\mathrm{SnBi}$ grain size was smaller, and the sample to which the SnBi filler of $\phi 20 \mu \mathrm{m}$ was added showed $17 \mathrm{~W} / \mathrm{mK}$, which was more than three times as high as the $\mathrm{Cu} 50$ vol\% sample.

(4) As the result of measuring the volume resistivity of the $\mathrm{Cu}$ filler-containing adhesive, the electrical conductivity increased due to the increase of the filler content ratio, and it became almost constant over 50 vol\%.

(5) As the result of measuring the volume resistivity of samples in which SnBi 10 vol\% and 20 vol\% was added to $\mathrm{Cu} 50$ vol\% conductive adhesives, it was confirmed that the sample with $\varphi 73 \mu \mathrm{m} \mathrm{SnBi}$ added was about 2 orders and the $\varphi 20 \mu \mathrm{m} \mathrm{SnBi}$ added was about three orders lower than the sample without $\mathrm{SnBi}$ addition. It shows the effect of reducing the volume resistivity due to the metal bridge formation.

\section{REFERENCES}

1) T. Matsumura and T. Yamamoto: Fujitsu Sci. Tech. J. 43(1) (2007) 5058.

2) K. Suganuma, K.-S. Kim, K. Toyofuku and K. Hagio: Materials Science \& Technology 2004 Conference \& Exhibition, (2004).
3) Y. Li and C.P. Wong: Mater. Sci. Eng. R 51 (2006) 1-35.

4) K. Suganuma, S.-J. Kim and K.-S. Kim: JOM 61(1) (2009) 64-71.

5) J.C. Bolger, J.M. Sylva and J.F. McGovern: Surf. Mount Technol. 6 (1992) 66-70.

6) L. Li, C. Lizzul, H. Kim, I. Sacolick and J.E. Morris: IEEE Trans. Compon. Hybrids Manuf. Technol. 16 (1993) 843-851.

7) M.A. Gaynes, R.H. Lewis, R.F. Saraf and J.M. Roldan: IEEE Trans. Compon. Packag. Manuf. Technol. B 18 (1995) 299-304.

8) U. Eitner, T. Geipel, S.-N. Holtschke and M. Tranitz: Energy Procedia 27 (2012) 676-679.

9) Y. Li and C.P. Wong: Mater. Sci. Eng. R 51 (2006) 1-35.

10) E. Sancaktar and L. Bai: Polymers 3 (2011) 427-466.

11) J.M. Kim, K. Yasuda, M. Rito and K. Fujimoto: Mater. Trans. 45 (2004) 157-160.

12) H. Hayashi, K. Konno, T. Kawamori and T. Tanaka: 14th Symposium on "Microjoining and Assembly Technology in Electronics", 14, (2008) pp. 437-440.

13) Y.S. Eom, K.S. Choi, S.H. Moon, J.H. Park, J.H. Lee and J.T. Moon: ETRI J. 33 (2011) 864-870.

14) E.S. Dettmer, B.M. Romenesko, H.K. Charles, Jr., B.G. Carkhuff and D.J. Merrill: IEEE Trans. Compon. Hybrids Manuf. Technol. 12 (1989) 543-547.

15) Y. Takechi, M. Matsushima, S. Fukumoto and K. Fujimoto: Proceeding of 22nd Symposium on "Microjoining and Assembly Technology in Electronics", 22, (2016) pp. 325-330.

16) M. Matsushima, Y. Takechi, Y. Mizokami, S. Fukumoto and K. Fujimoto: Proceeding of 23rd Symposium on "Microjoining and Assembly Technology in Electronics", 23, (2017) pp. 245-250. 